\title{
Day Times Millimole Per Liter Per Gram
}

National Cancer Institute

\section{Source}

National Cancer Institute. Day Times Millimole Per Liter Per Gram. NCI Thesaurus. Code C112254.

Days times millimoles per liter, divided by grams. 